\title{
Rapport annuel: nouvelle tentative
}

\section{Ursina Pally Hofmann}

Dre iur., Secrétaire générale de la FMH

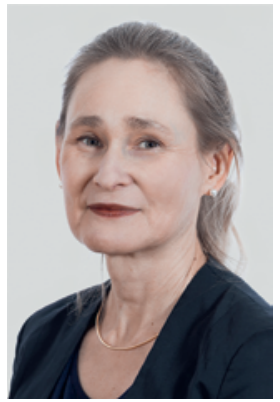

Les défis actuels liés au nouveau coronavirus (Covid-19) et à la manière d'enrayer l'épidémie préoccupent en ce moment l'ensemble de la population suisse. Les médecins mettent tout en œuvre pour appliquer les mesures ordonnées par la Confédération afin de continuer à soigner tous les patients qui ont besoin d'une prise en charge.

Malgré cette situation extraordinaire, la FMH remplit ses obligations statutaires et vous présente ses résultats pour l'année 2019, même si les statistiques sont formelles: le rapport annuel ne suscite que peu d'intérêt. Sur le fond, rien à redire. Un tel rapport n'a guère de rôle à jouer dans le quotidien des médecins.

En revanche, la FMH est légalement tenue de publier un rapport de gestion. Nous prenons très au sérieux

\section{Nous avons désormais choisi d'enrichir nos} textes par des graphiques et des contributions vidéo et audio.

cette mission à l'égard de nos membres et des tiers; il nous tient à cœur de présenter nos activités, et par là même de montrer en toute transparence comment nous employons vos cotisations.

Peut-être réussirons-nous à gagner quelques lectrices et lecteurs supplémentaires, ou plus exactement de nouvelles spectatrices et de nouveaux spectateurs, grâce au nouveau format que nous avons adopté cette année. Nous avons en effet désormais choisi d'enrichir nos textes par des graphiques et des contributions vidéo et audio.

Vous trouverez le rapport annuel dans ce nouveau format beaucoup plus attrayant à nos yeux à l'adresse www.report2019.fmh.ch. Suivez ce lien et faites-vous votre propre idée!

Nombre de renseignements juridiques donnés

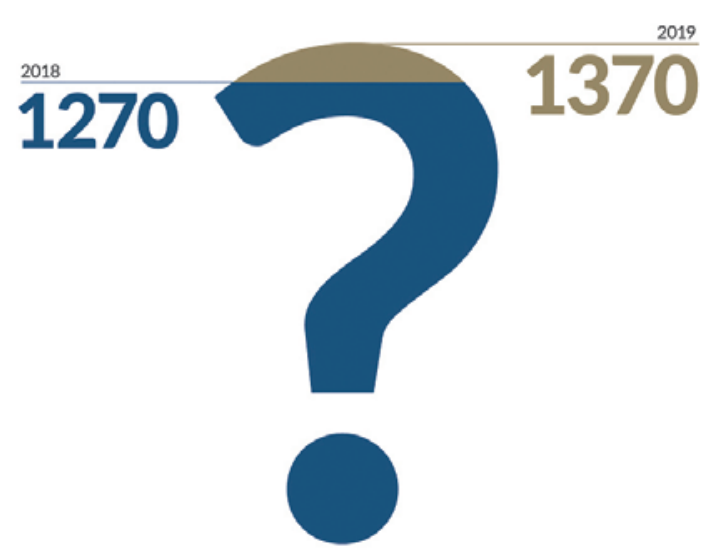

Anticipation des taux d'activité de demain

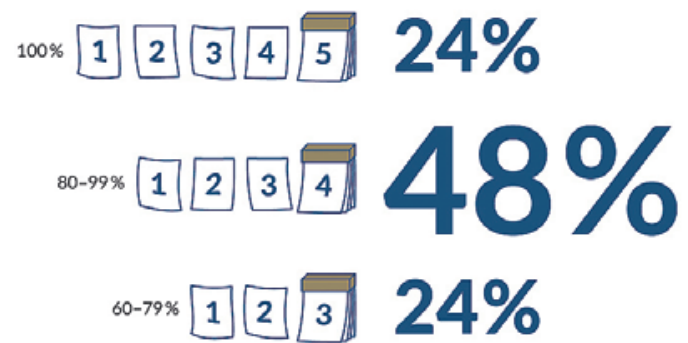

Prévention

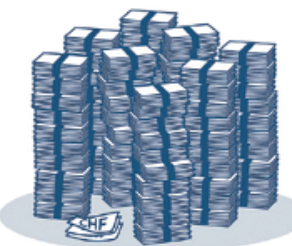
1,98 milliard 